\title{
A Knowledge Management-based Decision-making Model for Planning Patient Discharge in the UK National Health Service
}

\author{
Nitya Kamalanathan \\ Staffordshire University \\ Stafford, UK
}

\author{
Alan Eardley \\ Staffordshire University \\ Stafford, UK.
}

\begin{abstract}
The UK National Health Service (NHS) is faced with problems of managing patient discharge and preventing the problems that result from it such as frequent readmissions, delayed discharge, long waiting lists, bed blocking and other such consequences. The problem is exacerbated by the growth in size, complexity and the number of chronic diseases in the NHS. In addition, there is an increase in demand for high quality care, processes and planning. Effective Discharge Planning (DP) requires practitioners to have appropriate, patient personalised and updated knowledge in order to be able to make informed and holistic decisions about a patients' discharge. This research examines the role that Knowledge Management (KM) plays in planning an effective discharge plan. The research examines existing ways in which DP is currently carried out, the stakeholders involved in the DP process and highlights areas requiring further improvement. This research also examines KM models in healthcare and integrates KM with DP in the form of a KM based DP model. The model was developed based on primary research carried out on the stakeholders of DP along with secondary research. The model intends to highlight the nuances that require focusing on, and provides a seamless overview allowing healthcare personnel to impeccably plan the discharge of a patient with the involvement of both patients and their carers. The KM-based DP model is validated by the actors involved in planning the discharge i.e. healthcare personnel. Patients and carers too are involved in DP; however their involvement is focused on their knowledge and experiences influencing the decisions being made. Healthcare personnel such as doctors, nurses and administrators are however actively involved in planning the discharge.
\end{abstract}

\section{General Terms}

DP - Discharge Planning. KM - Knowledge Management. DH - Department of Health. NHS - National Health Service.

\section{Keywords}

Knowledge Management, Healthcare, Discharge Planning, Patient Pathway, Electronic Health Records, Clinical Portal.

\section{INTRODUCTION}

An essential component in quality healthcare is the convalescence of a patient and DP plays a key factor in a patient's convalescence [1]. Various factors play instrumental roles in DP and involve patients being transferred from one care environment to another. Careful planning and a clear framework are vital to the smooth flow of patient care upon arrival to the end of post treatment, along with ensuring the efficient use of hospital resources [2].

\section{DISCHARGE PLANNING}

DP facilitates patients moving from one healthcare setting to another, or to their home. Discharge from hospital is a process and not an isolated event' [3] and DP is the beginning of a patient's convalescence. It begins on admission and is a multidisciplinary process involving physicians, nurses, social workers, and possibly other health professionals [4] [2] [5]. The better the DP process and the discharge plan, the smoother the convalescence of the patient, as it ensures the patient, their family and carers are collaboratively involved in the process, ensuring that they are equipped with the knowledge they need for a smooth convalescence. The aim of DP is to enhance continuity of care and it can have significant implications on a patient's well-being and recovery, the effectiveness of hospital management processes and the efficient use of medical resources. The complexity of the discharge process implies that careful planning is needed to make the process effective [3] [1].

Better DP can provide advantages to the "stakeholders" of the DP process i.e. patients, their families, social workers, healthcare personnel and the healthcare organisation as a whole [3]. The advantages to the stakeholders includes, patients feeling actively involved in the planning process, carers have the right information and advice to help them in their caring role, healthcare personnel receive key information at a timely manner, and the healthcare system meets its targets and can focus on delivery amongst several other reasons. These areas need to be focused on in order to ensure DP is aligned appropriately, such as patient and carer involvement and empowerment, improved processes, healthcare personnel being presented with the right information at the right time to make informed decisions, awareness of certain roles and responsibilities and meeting established targets.

\subsection{Discharge Planning Guidelines}

The Department of Health (DH) has created a general outline of guidelines for effective discharge procedures. Based on the guidelines, patient and carer needs appear to be considered, and their involvement in the DP process is emphasised. However, a clearly defined process indicating the knowledge required for an action; the sources of the knowledge; efficient means of retrieving knowledge; emphasis of knowledge sharing and communication which encourages reasoning before making a decision pertaining to patient discharge within departments in the NHS and the consequent series of steps that need to be taken appear to be lacking. Many NHS trusts use a discharge checklist with questions to ask patients and to note and check about a patient. Discharge checklists follow the framework provided by the $\mathrm{DH}$ guidelines [2]

It can be seen from the checklist [2] that questions are asked about a patient's mobility, social circumstances and nutritional intake. Carer involvement is highlighted and transport arrangements are listed to be checked as well in the discharge policy. However an indication of how to measure the outcome of the checklist is not presented. An indication of the knowledge reasoning, extraction and management is 
missing such as what boxes should be ticked; in the event that a particular box is not ticked what actions should be triggered; the sources of knowledge in order to make an informed decision; evidence of sharing of knowledge between different departments; and in the event a change in shift were to occur between nurses what would happen is lacking from the discharge checklist. Healthcare personnel such as a doctor and nurse would evaluate the results on the sheet and from their experience, make a decision on whether the patient should be discharged or not. Questions such as a patient's and carer's readiness for discharge, an indication of how to communicate the information to patients and carers, providing patients and carers with information about their prognosis, symptoms, nutritional and exercise recommendations was lacking. Information that would help a patient's convalescence at home seemed to be lacking in the discharge policies of the NHS Trusts.

\subsection{Obstacles To Discharge Planning}

Much of the activity in healthcare involves charting and paper-based activities. Information that is collected by healthcare personnel is noted on paper in most NHS Trusts, and at the end of the week healthcare personnel are faced with the burden of paper work [6] [5]. This results in the inability to analyse the information and the inability to capture the knowledge that exists efficiently. Some information might even be lost [4]. Several factors affect the adequate planning of discharge. Hospitals are hampered with many processes including backend processes which patients do not see. Different departments can be involved in a patient's discharge, which requires sharing of information in a timely manner between departments. In order to provide patients with the best treatment, while efficiently managing costs and resources in the NHS, technologies such as clinical portals and electronic health records can be implemented [7] [8] [9]. This can result in faster, smarter, more accurate and personalised DP. It is a world of information and connectivity, and computers, the web, search engines have all become an indispensible part of life, and has transformed the way that knowledge is shared and created [10]. Information architecture is important, and the organisation of information is equally important enabling its easy access [11] [12]. Poor information sharing between departments can result in errors such as lab test errors, medication errors, communication error and wrong diagnosis [13], all of which jeopardise a patient's safety. Patient safety involves identifying, analysing and managing patient related risks and incidents, making patient care safer and minimises harm to the patient [13] [14].

'The vast majority of NHS care is safe, but mistakes do happen, sometimes with tragic consequences. We can only prevent these problems if we learn from what goes wrong'

For efficient DP, information required for informed decision making should be organised in such a way that the information required is collected, stored, distributed and used by the people requiring the information at the time required [15] [16]. This allows for data and information to be aggregated and processed to generate knowledge which as a result allows for more intelligent and informed decisions to be made, this improving DP with insight [17] [18] [19]. The processes in the NHS pertaining to DP can be likened to Swiss cheese, with many holes in it, symbolising the siloed way in which the different departments operate. This research intends to smooth out the processes and 'cheddar the DP process' and turn data into insight, insight that can help make multidisciplinary meetings more interactive, allow faster reaction times, enhance information sharing between departments real time, allowing clinicians to react quickly and allow for better decisions to be made while clinicians are at the point of decision making. Synthesising information by the various stakeholders of the DP process and information about patients relevant to the decision making process is vital to ensuring errors such as the lack of considering peripheral medical factors of a patient, which may result in a patient being readmitted if not taken into consideration.

Hannan, [20] states that patients, carers and information are the most underutilised resources the NHS has. It is the patients who are faced with the symptom, and the carers who look after the patient, the knowledge they have is most valuable to making decisions, which unfortunately is currently overlooked. Each patient has a unique problem and personalising the discharge process will reduce the current problems faced in DP. Ensuring that patient and carer involvement commences at the beginning of DP is important, as their involvement determines the coordination of resources that will be needed for the patient upon discharge at an earlier stage. Triggering the coordination of resources and communication with care agencies at an early stage is important for preventing problems such delayed discharges caused by a patient having recovered but having nowhere to go due to lack of availability of a care home. If the communication process and coordination of resources occurs at an earlier stage it minimises delays in discharge, ensuring a care facility is allocated to the patient, as it allows care homes and carers sufficient time to make the necessary arrangements and create the availability of resources [21] [22] [23].

There is a mismanagement of resources and time as different teams operating in the operating theatre; ward and community often repeat the same practices and develop new methods repeatedly, rather than sharing what they know via reliable national networks so that they can learn from each other [24]. This is sometimes termed a silo mentality [25]. Paul Batalden, Director of Healthcare Improvement and leadership development at Dartmouth Medical School says that "People in medical training are prepared to work in a silo" [25]. The problem of hospital units performing as silos in relation to DP, apart from their inability to exchange 'best practice' are the detrimental effects on patient treatment e.g. double dosing of medication at admission and discharge [25] and 'bed blocking', delayed discharge and increased emergency readmissions [26]. There are also management implications for instance, financial strains and procedural ineffectiveness and effects on staff efficiency for instance the employees find themselves overwhelmed with bureaucracy [27].

The NHS like many organisational systems is brimming with data and information but accessing this information in order to make a decision seems to be a challenge due to its fragmented nature. Recent years have witnessed advances in Informatics i.e. the use of Information Technology to increase productivity and efficiency in healthcare [28]. Data when stored provides very little functionality to an organisation as it is not able to provide instructions to the organisation on what to do. Knowledge on the other hand is a collation of experience, values, contextual information and expert insight that provides a framework for evaluating and incorporating new experiences and information [29]. The NHS is currently faced with the problem of "islands" of data and information in the form of silos that prevent the efficient flow of information between departments in an organization [30]. Very little knowledge is extracted from these silos, leading to the foundations of this paper, a $\mathrm{KM}$ model that provides an 
integrated approach to identifying, managing and sharing the "islands of knowledge" in order to identify an appropriate patient discharge pathway. KM forms the bridge between these isolated islands of knowledge [24].

Quantitative measures such as the targets currently determine a patient's discharge as reported in the popular press, and the problems resulting from this situation have received a great deal of attention from the press recently and over the past decade. Targets are given priority while a patient's quality of care is compromised [31]. The implication of being target driven rather than knowledge driven is that the healthcare system fails to consider all factors that result in the effective recovery of a patient post treatment [32] [4] [2]. It focuses on accomplishing and achieving targets resulting in doctors and nurses compromising patient safety and well being. Doctors have been reported in the popular press to make quick and rash decisions about patients just to get the "clock to stop ticking" [33] resulting in deteriorating trust between doctors and patients. Doctors find themselves torn between meeting targets and providing their sick patients with the best treatment. These claims in various news media have been reaffirmed by Andrew Lansley the Secretary of State for Health in the UK who in a speech in December 2011 stated that:

'The NHS is full of processes and targets, of performance management and tariffs. Originally, all designed to deliver better patient care. But somewhere along the line, they gained a momentum of their own, increasingly divorced from the patients who should have been at their centre.' [34].

\section{PROBLEMS WITH INADEQUATE DP}

A preliminary review of the problem from sources such as press reports, anecdotal evidence and literature from the NHS suggests the problems resulting in inadequate DP were insufficient personalised patient knowledge; lack of informed decision making; focus on targets; insufficient holistic approach; lack of resource coordination and a lack of communication.

These factors result in delayed discharge and increased emergency readmissions. The consequence of delayed discharge and emergency readmissions was bed blocking and long waiting lists, all of which affect the admission, transfer and discharge of a patient. The factors contributing to poor DP result in one or more of three common problems (i.e. problems with admission, transfer and discharge) [18] [35] [36] [37]. The problems of inadequate DP from the literature review are succinctly identified in a diagrammatic representation as seen in Figure 1 and was further researched into during the primary research and analysis phase of the research.

\subsection{Increased Emergency Readmissions}

Increased readmissions, a complex situation caused by a variety of factors, reflect poorly on patient management. Increased emergency readmissions commonly occur when patients have been discharged too early. When the reasons for emergency readmissions to hospital were examined, poor communication between hospital and community support organisations was identified as a main reason [38]. It was also found that insufficient information was passed on to care agencies that if overlooked could have effects that result in a patient requiring admission into hospital again [39] [40]. A study by The Royal Pharmaceutical Society of Great Britain, 2006 found that between $19 \%$ and $23 \%$ of patients who were discharged experience an adverse event after discharge. It is suggested that $60 \%$ of unplanned readmissions could be avoided by more effective action at the time of discharge. [41]. Kaiser Permanente in December 2010 reported that most readmissions are for a reason different than the original admission, with only $5 \%$ being for the same reason and, of the patients who are readmitted within 30 days, $30 \%$ pass away within 6 months in the UK [42].

\subsection{Delayed Discharge}

A delay in discharge occurs when;

$$
\begin{aligned}
& \text { '...an inpatient who has been judged clinically ready } \\
& \text { for discharge by the responsible clinician in } \\
& \text { consultation with all agencies involved in planning } \\
& \text { that patient's discharge, and who continues to } \\
& \text { occupy the bed beyond the ready for discharge } \\
& \text { date'. }
\end{aligned}
$$

Delays in discharge may compromise the quality of patient care, and reflects a lack of efficiency and effectiveness within the continuum of care and service coordination [44]. Some reasons linked to delayed discharge include [45] [26] [46] [43] include; too many patients admitted to hospital, despite viable alternatives; patients moved inappropriately around between wards; and a lack of process and process delays which were compounded by system problems. Figure 1 shows that the consequences of poor DP are interconnected. Emergency readmissions result in bed blocking and long waiting lists which affect delayed discharge and vice versa. The 'front-door' issues need to be addressed as well as the 'back-door' [43].

Delayed discharge from hospital is caused by both medical and non-medical reasons, and $30 \%$ of all hospital discharges have been due to non-medical reasons [1]. 20\% of hospital stay was seen to be inappropriate and approximately $45 \%$ of these inappropriate hospital stays were mainly due to nonmedical reasons [47]. This therefore proves that the nonmedical reasons such as after care, facilities to recover at home, and various other related reasons need to be investigated and considered in a KM model that is proposed in this paper. Delayed discharge has seen to pose a threat to a patient's morale by causing problems such as depression, over dependence on hospital staff, lack of confidence and other related problems [48].

\subsection{Bed Blocking}

Bed blocking occurs most frequently when patients in wards, awaiting discharge, are held back due to volumes of paper work that hospital staffs are excessively involved with, amongst other reasons [48]. Some patients are delayed from six to fifteen days, while many other inpatients, awaiting treatment are made to wait or even declined treatment [49].

\subsection{Long Waiting Lists}

Longer hospital waiting lists result from to delayed discharge and a backlog of inpatients awaiting their turn to be treated [50]. This causes long waiting hours, and builds frustration amongst patients. If the average annual cost of an acute bed is $£ 120,000$, and approximately 6000 beds are occupied by patients who should have been discharged, annually the NHS wastes approximately $£ 720$ million [2].

\section{KM SOLUTION TO DP IN THE NHS}

In an organisation, the major challenge is to create a $\mathrm{KM}$ system to the benefit of an organisation that can; 
'...acquire, conserve, organise, retrieve, display and distribute what is known today in a manner that informs and educates, facilitates the discovery of new knowledge and contributes'. [51].

$\mathrm{KM}$ can be looked at as an integrating practice that offers a framework for balancing the myriad of processes, technologies and approaches that provide value [52]. It ties them together into a seamless whole by aligning organisational information and practices with the organisation's strategic objectives, fits into employee's daily work activities, manages content effectively, and considers the potential business opportunities associated with sharing knowledge with suppliers and customers [53]. As a result of this, KM better enables individuals, systems and organisations to exhibit intelligent behaviour in a dynamic and agile environment [54]. $\mathrm{KM}$ is about disseminating the right knowledge to the right people at the right time in order to make informed decisions [55] [56]. With regards to DP, various departments are involved in the decision making process [22]. Therefore the ability of $\mathrm{KM}$ to enhance collaboration and decision making proves to be advantageous as having the right information and knowledge is important to efficient DP. The ability of KM to seamlessly align an organisation's information, practices and people encourages informed decision making, and in the case of the NHS, aligning the 'stakeholders' of DP i.e. the patients, carers and healthcare personnel, with the practices with regards to DP. The use of technologies where needed, will then allow for more efficient DP processes.

KM will set a foundation for allowing the current knowledgerich resources in the NHS to be used effectively in order to make more informed decisions regarding DP and to overcome the current obstacles to DP, namely the focus on quantitative measures, the organisational silos, and the poor coordination of resources in the NHS. KM will allow for the fragmented processes, as it will identify the problematic areas, and provide knowledge-based solutions that will work to the benefit of all the 'stakeholders' in the DP process. Knowledge captured and shared can be used for strategic decision making processes such as planning a discharge of a patient while ensuring that all the related factors internal and external to the Healthcare setting are taken into consideration. It also allows for the prediction of trends, disease patterns and the overall management of the Healthcare setting while being patient-centric and complying with targets that have to be met.

\section{KM FOR DISCHARGE PLANNING}

A hospital is a dynamic environment, with changes taking place rapidly and consists of complex components interacting with one another. Fluidity between these components is imperative for ensuring a smooth flow within the system. DP similarly involves changes from a temporal stable state to another with an unpredictability of what is to happen next [57]. It is here that the past experiences of doctors and nurses in assessing a situation, deciding on a plan and decision making is useful as during the decision making process, previous knowledge gained by the personnel who actively engage with patients can be extended to fit the situation or the patient at hand [57]. The tacit and implicit knowledge possessed by personnel actively engaged with patients is useful in these situations in order to provide a personalised approach to assessing a patient and their journey in the hospital along with following a codified guideline. KM aims to solve the bottlenecks that occur in the various departments currently in the NHS, in order to improve the DP process through knowledge mapping and identification of possible opportunities for improvement [58]. Factors requiring coordination for the convalescence of a patient, and several barriers to discharge planning can be classified as, internal communication, communication between different departments and healthcare personnel within the NHS; external communication, communication between the NHS and external agencies, including patients and carers; a lack of personalised knowledge of patients and carers; an insufficiently holistic approach; poor resource co-ordination; meeting targets and avoiding human error. The coordination of these seven components will help to improve the problems currently faced by inadequate DP, as a more holistic and personalised approach is taken, helping to maximise efficiency and to co-ordinate resources in the NHS, while saving costs in the long term, improving coordination and communication with the external community and care resources and improving patient satisfaction. The barriers highlighted above have resulted in problems such as delayed discharge, increased emergency readmissions, long waiting lists and bed blocking, all of which have been attributed to poor DP [59] [39] [22].

The KM Model that will be presented in Section 5 (see Figure 2) will encapsulate the problems with regards to DP as identified in this research through both primary and secondary research, which includes interviews with healthcare personnel, patients and carers and proposes technological solutions in order to improve the DP process for a more personalised or patient centred approach.

\subsection{Definition of Terms in the KM Model}

The KM-based decision-making model for DP includes 7 components or factors, as follows:

1. Knowledge requirements - A knowledge requirement is the information that is needed to trigger the commencement of the informed decision-making process (i.e. the need to produce a patient discharge plan);

2. Knowledge assets - Knowledge assets are the knowledge bases, tools and technologies that inform and enable the informed decision making process;

3. Knowledge actions - The actions (e.g. data collection, information analysis) that are taken to produce the required knowledge;

4. Knowledge outcome - The cumulative output of the decision-making process (i.e. derived from the knowledge requirements, the knowledge assets and the knowledge actions in steps 1-3);

5. Management and Environmental factors - 'the real world' factors which may affect the overall discharge plan, but which when $1,2,3,4$ are coordinated, subsequently fall into place as well. It is therefore important to be mindful of these factors and ensure that constraints and possibilities that arise from them (e.g. economic and social conditions) are taken into account;

6. Discharge plan - The end product of the process, which is produced from the previous five components and steps;

7. Lessons from the discharge plan - The lessons that have been learned through the steps in the process and the use of components 1 to 6 are updated to further improve future discharge plans and the discharge planning process. These 'learnings' will be used to update and improve the knowledge assets (component 2). 


\subsection{Knowledge Outcomes}

In order to come up with a better discharge plan, several knowledge outcomes (component 4) have been highlighted as important. These include having personalised knowledge about a patient using improved communication within the communication layer, the improved external communication layer.

\subsubsection{Improved Internal Communication}

The second knowledge outcome as seen in Figure 2 consists of two components, namely, improved internal communication and updated personalised patient information. In order to achieve these outcomes, the knowledge required is, Healthcare personnel knowledge. Healthcare personnel like doctors and nurses have information about how they treated a patient with a similar diagnosis previously, and they might have knowledge about the patient being treated from the conversations they have had over time with the patient. Capturing tacit knowledge of the healthcare personnel, (i.e. their 'know how') adds value to the overall decision to discharge making process, as it ensures that a personalised approach is taken. Information from different departments such as laboratory test results, x-ray and scan images, doctors' notes, notes from different departments etc. Knowledge from healthcare personnel can be best captured in knowledge assets such as the Map of Medicine which provides a best practice and diagnostic pathway. The Map of Medicine 'supports the optimisation of care by providing access to comprehensive, evidence-based guidance, and clinical decision support at the point of care' [60]. Therefore a localised "Map of Medicine" can help greatly, to provide information required by healthcare personnel at the point of care, at the same time prompting healthcare personnel to look for information relevant to decision making in electronic health records. Electronic health records can contain large amounts of information and knowing what information is needed at the point of care is important [8], hence the significance of a localised "Map of Medicine".

Information from different departments can be best captured using assets such as a prediction tool that calculates the risk of readmission and which provides information that a healthcare personnel might need such as the electronic patient records, information from different departments such as laboratory test results, x-ray and scan results, doctor's notes, notes from different departments etc. The portal helps with the sharing of information conveniently between departments, reducing the waiting time that currently occurs between departments [9] [61]. The portal can be easily accessed by the healthcare personnel and assists in presenting the information from different departments as previously described. Personalised patient information, when linked to the portal, allows for this information being presented to healthcare personnel at the point of decision making, ensuring that personalised information about the patient is present, coupled with their existing tacit 'know how' to make informed decisions. Another knowledge asset which serves a useful includes a tool which predicts the risk of a patient being readmitted. This tool runs an algorithm, which predicts the likelihood of the patient being readmitted based on the personalised information about the patient such as the Predicting and Reducing Readmission to hospital (PARR) risk prediction tool. When knowledge assets are shared internally within different departments in the healthcare setting, a knowledge action is taken. This action ensures that healthcare personnel make more well-informed decisions. Having personalised patient information, coupled with the 'know how' of the healthcare personnel and the risk of a patient being readmitted allows for more informed decision making at the point of DP. It allows decisions such as whether the patient should be transferred to a care home, whether the patient will require someone to attend to them regularly, etc., to be made at an earlier stage of DP. The knowledge outcome at this level feeds in to the discharge plan (6), influencing the informed decision making process, and is perused in the next level as well.

\subsubsection{Improved External Communication}

The knowledge outcome of the Improved External Communication layer as seen in Figure 2 is patient empowerment as the patients receive knowledge that is required to help them to recover at home to be aware of the consequences of their actions and also improve interagency collaboration. Improved interagency collaboration is key to DP, hence it being strategically located at the bottom right corner of the model (i.e. last in the knowledge sequence). The purpose of its location is to indicate that before a discharge plan is signed off, it is important that various external agencies that have to be contacted have been contacted, the necessary information that needs to be shared is shared in order to ensure a smooth discharge transition and prevent potential delayed discharges or lack of timely knowledge about a patient. In order to achieve this outcome, the knowledge required is the collated knowledge from the previous two layers. This knowledge can be found in the portal, and a patient canvas, the knowledge assets (2). The portal will provide patients with online access to their healthcare records, with an explanation of their diagnosis, symptoms, medication consumption, all explained in an easily understandable form [62]. It would also include nutritional and exercise recommendations, and links to recommended websites for further reading, videos, podcasts etc. If patients are uneasy with the use of a patient portal, a patient 'canvas', a short description provided to patients about their diagnosis, symptoms, medication explanation, and exercise and nutritional recommendations. This information should be shared externally, as the knowledge action that needs to be taken. This would result in patients being provided with the necessary information to recover at home.

Information about patients should be shared externally with external care agencies at the point of admission so as to ensure that care agencies have up-to-date information about a patient at a time when they are taking care of the patient to avoid any errors that could happen. Care agencies could be linked to the portal to have access to the patient information, information that is relevant to the care of the patient. The outcome of sharing information with patients and collaboration with care agencies is fed in to the discharge plan (6), ensuring the discharge plan incorporates a holistic approach.

\subsubsection{External Factors}

These factors are invariably related to DP. When the core factors are aligned, such as personalised patient knowledge, shared information between departments in the hospital and with patients and carers, the management and environmental factors are also aligned as a result. A Root Cause Analysis in two UK acute hospitals [51] suggested that the following improvements can be achieved by applying the KM-based DP model:

\subsubsection{Reduction in Human Error}

The use of the clinical portal to link personalised patient information and the knowledge of the healthcare personnel in the form of the map of medicine, and knowledge about the 
treatment, diagnosis and results of a patient will as a result ensure that patients are identified correctly, it will minimise a wrong diagnosis, lab test errors, medication errors and communication errors. It therefore will minimise human error.

\subsubsection{Better Resource Coordination}

Having the information that is needed when it is needed will help to coordinate resources better, staff will be assigned tasks according to their roles and responsibility, a bed management system will be in place, the discharge plan will be documented and can always be tracked, care resources and medical equipment if needed will be booked in advance using the personalised patient information.

\subsubsection{Improved Achievement of Targets}

Targets such as the number of patients discharged, minimizing emergency readmissions can be met more easily if the processes as described above are aligned. It will be ensured that more patient-centric targets are in place and that cost and expenses will be better managed as better processes are in place.

\subsubsection{A Holistic Approach}

A holistic approach will be ensured by using the "Map of Medicine", the clinical portal and electronic patient records, as the multiple pathology of each patient will be recorded, hidden sources of confusion can be identified, healthcare personnel will have more accountability as they will be assigned tasks according to their roles, and more informed decision-making will take place as personalized patient information is used, alongside capturing the 'know-how' or tacit and implicit knowledge i.e. tacit knowledge that is capable of being made explicit of healthcare personnel.

Having all information needed in place, it is proposed that a better discharge plan (component 6) can be produced. The lessons learned (component 7) from the discharge plan will be fed back into the DP process in order to ensure a continuous improvement in the process.

\subsubsection{Discharge Plan}

All the three levels of the KM model feed back to the fifth part, the discharge plan. The discharge plan is the knowledge achievement. The discharge plan produced is personalised to the patient and is produced in a way to mitigate future complications in terms of emergency readmissions that might occur. It is also produced in a timely manner thus minimising delayed discharge. The feedback obtained from the discharge plan, which can be obtained by monitoring the statistics of emergency readmissions, delayed discharge, waiting lists, patient satisfaction, healthcare personnel satisfaction, noting lessons learned, and other such information to gauge the success of the measures taken, is used and fed back (e.g. in component 6 .

\subsubsection{Lessons from the Discharge Plan}

The lessons learned from the outcomes of the DP, when tracked, monitored and documented, can help in constant refining of all the steps. In other words, the hospital can become a learning organization and improve its DP process in future by updating its knowledge base.

\section{CONCLUSION}

A major part of this research was to understand the current initiatives of DP and the tools and technologies that currently exist and that are currently being used. When proposing the use of knowledge assets, it was ensured that the assets were those that currently exist, as they themselves are rich in knowledge and are underused. The aim of the research was therefore to make the best of the existing assets and extract the information needed to make knowledge based decision.

The first recommendation from the research is for the NHS to make the best use of web portals as knowledge assets, rather than simply web interfaces. Portals have been developed and actively used in Trusts such as the Christie Trust and NHS Scotland, amongst other NHS Trusts to enhance information sharing. The feedback from the trusts has been generally positive and talks are underway in some trusts for an integration of the portal with patient records in order to allow patients access to their records and information [62]. The current portals are used by healthcare personnel to share information such as clinical notes, PACS, test results, physicians notes and GP notes [63]. Linking the local "Map of Medicine" which provides localised pathways and the electronic patient records to a portal will help provide patients and healthcare personnel with information relevant to them at the time needed, helping to empower patients with knowledge about themselves and to empower healthcare personnel to confidently make informed decisions [64] thus reducing possible human errors (one of the environmental and management factors highlighted in the model).

The second recommendation concerns the use of the Map of Medicine as a way of promoting best practice in patient care and treatment. The Map of Medicine has helped to standardise care by generating evidence based pathways that have been established as a means of best practice [60] the pathways guide both the healthcare personnel and patients with different user views and customized to suit the understanding of the different user. The pathway helps to enhance the accuracy of decision making and helps to ensure that the information needed is sought and used in order to make informed decisions.

The third recommendation concerns the use of suitable Risk Prediction Tools to minimize the risk to patients when decisions on discharge are being made. Recent years have witnessed advances in Informatics (i.e. the use of information and communications technology or ICT) to increase productivity and efficiency in healthcare [28] and 'big data' (i.e. large amounts of stored data) may be of help to decision makers in practice. Data, when stored, provides very little functionality to an organization as it is not able to provide instructions to the organization on what to do. Therefore the extraction of knowledge from the 'big data' can generate insights that can result in efficiencies [65] [66]. Analytics tools such as risk prediction tools which are already being implemented can help provide insight into patient DP, such as provide analytical insights into the likelihood of patients with a particular condition being re-admitted and the likelihood of occurrences in various trusts across the UK. These insights could help trusts be better prepared with their internal and external communication. Analytical tools can be further extended into future areas such the analysis of data about patients to provide care from home, thereby minimising patient visits to hospital and admission, thus helping to free up beds. An example of such a risk prediction case-finding tool is also known as PARR - Patients at Risk of Re-hospitalisation. The tool systematically identifies patients who are at risk of readmission by accessing statistical information stored in the Hospital Episode statistics and has pre-set criteria or also known as risk factors which it runs the analysis alongside in order to determine the risk of a patient being readmitted [67]. The reason the PARR was suggested was so it could be incorporated to the portal and provides alerts indicating to the 
healthcare personnel if a patient is at risk of readmission at an early stage in the admission process, while planning for discharge. This will therefore trigger a set of actions for healthcare personnel to take (as seen in the model) such as undertaking inter-agency collaboration, acquiring information from patients and carers and checking previous records of patient history in order to make an informed decision that will prevent the "revolving door" situation which commonly occurs with patients currently [5].

The fourth recommendation is for the NHS to explore and develop the idea of a personalized Patient Canvas as part of the discharge plan. The patient canvas was proposed as a means of providing patients who are not too familiar with the use of computers and the internet with a simplified description of their prognosis, symptoms, medication description along with nutritional and exercise recommendations and links to further reading and help line numbers. During the patient participation group exercise the hesitance of patients to try using the computer and the Internet emerged, similarly during the primary research when talking to older patients who also complained about the thick booklets of generalized information with which they are provided and which they do not read. Therefore the patient canvas is a suggestion intended to help patients who are hesitant to use computers by providing them with the information they need in a concise format and help to reduce their resistance to using computers by providing encouragement through suggested links which can also possibly build curiosity in patients and therefore increase their knowledge and self-dependence.

Treated as holistic approach integrating various steps, components and technologies into a cogent patient-centric method and model of DP, the proposed KM-based decision- making model provides an innovative solution to the problem of DP in the NHS. The model represents a new approach to viewing DP, without changing too much of the current system. The model represents a means of bridging current silos and using existing technologies in the NHS in an improved manner. The model aligns the people, processes and technologies in a healthcare system in relation to DP, highlighting the knowledge requirements, assets, actions and outcomes, thus ensuring accountability of the people dealing with discharge on a regular basis, and allowing the information required for the informed decision making to be presented to them in an easily understandable and efficient form. The KM-based DP model allows healthcare personnel in the NHS to use the model to better understand the various components that need to be looked into when planning discharge. The DP model also highlights the importance of patient and carer involvement. The DP model can be used by discharge planners and member of the multidisciplinary team to further build on the model and generate further material based on the model, in order to make the DP process easier for healthcare personnel dealing with discharge. The DP can also be used by project planners and systems developers to integrate existing systems, such as The Map of Medicine, Risk of Readmission Tools, Electronic Patient Records and other such existing technologies into a central portal that helps present the knowledge needed in a concise form, in a timely manner to the people who need and have the knowledge, helping them form informed decisions. It also allows for a generation and input of lessons learnt, thus constantly building on existing knowledge. The KM based DP model acts as a base, on which existing tools, technologies and processes can be built on.

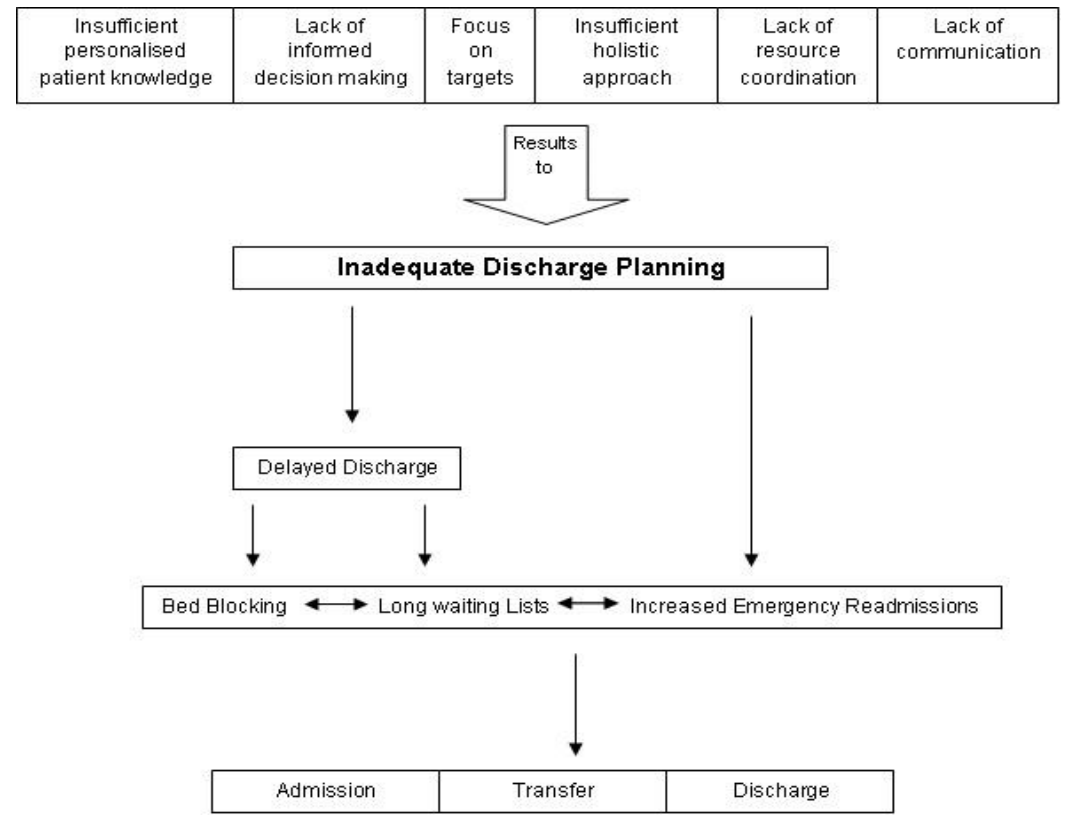

Figure 1: Consequences of poor discharge planning 


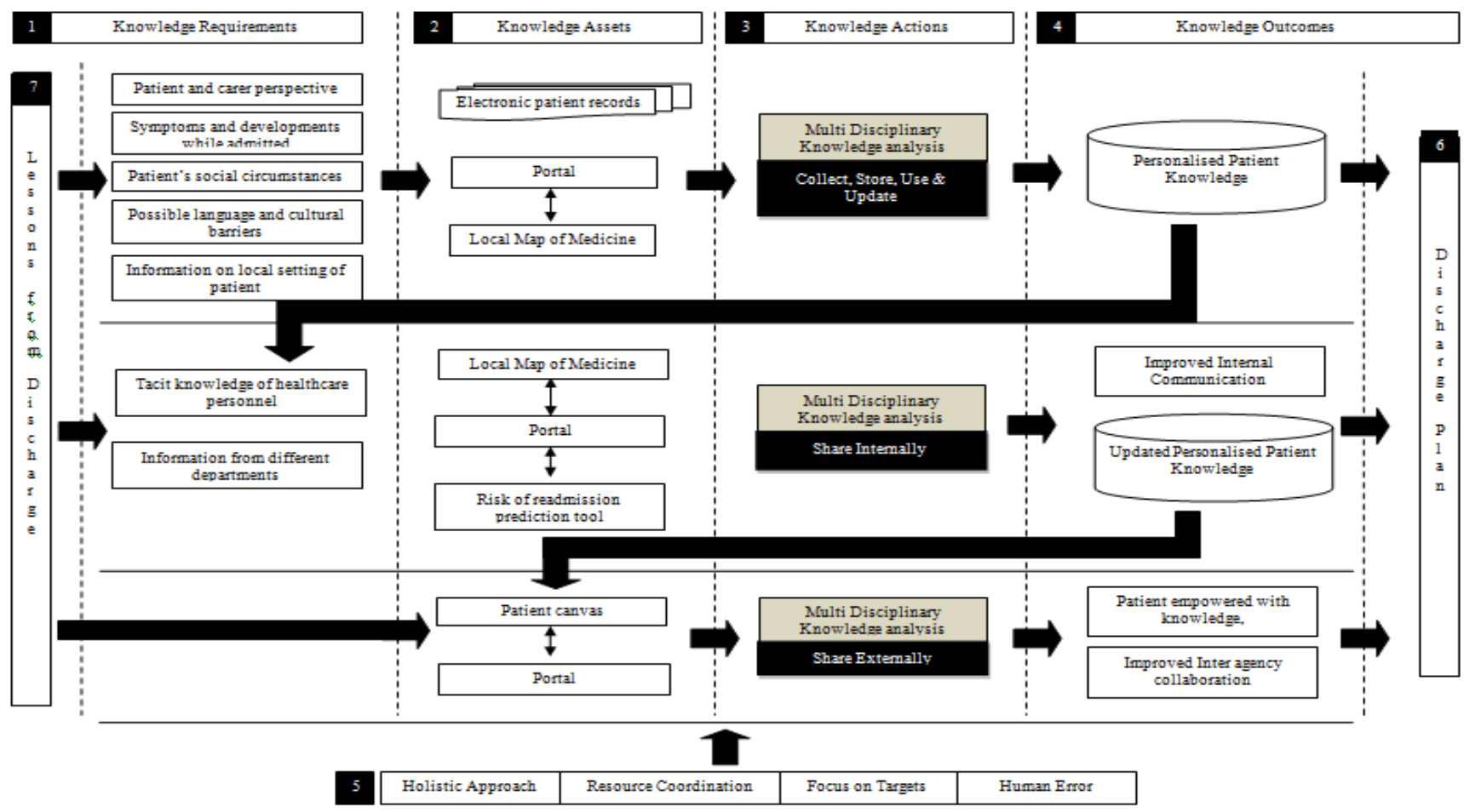

Figure 2. Knowledge based Discharge Planning Model

\section{ACKNOWLEDGMENTS}

Acknowledgements are due to Dr. Richard Fitton, Dr. Amir Hannan, the doctors and nurses of The Christie NHS Trust and of South Staffordshire and Shropshire Healthcare Trust for their participation in this research, particularly for their assistance in constructing and validating the model in Figure 2 .

\section{REFERENCES}

[1] Shepperd, S., McClaran, J., Phillips, C., Lannin, N., Clemson, L., McCluskey, A., Barras, S. (2010). Discharge planning from hospital to home. The Cochrane Library, (1), 1-75. Retrieved from http://onlinelibrary.wiley.com/doi/10.1002/14651858.CD 000313.pub3/pdf. Accessed 5 ${ }^{\text {th }}$ December 2014.

[2] NHS Institute for Innovation and Improvement. (2010). Ready to go - no delays (pp. 1-30). Retrieved from http://www.institute.nhs.uk/images//documents/Building Capability/HIA/7.Ready to go.pdf.

[3] Mudge, J. (2003). Discharge from hospital: pathway, process and practice (pp. 1-114). London. Retrieved from

http://www.wales.nhs.uk/sitesplus/documents/829/DoH Discharge Pathway 2003.PDF.

[4] Institute for Healthcare Improvement. (2011). Reducing Avoidable Readmissions. IHI.org. Retrieved June 27, 2013,

from http://www.ihi.org/offerings/VirtualPrograms/Expedition s/Reducing_Readmissions/Pages/default.aspx?gclid=CN Xls i sKoCFZRc4Qod4S1G7Q. Accessed $5^{\text {th }}$ January 2015.

[5] Sg2 Healthcare Intelligence. (2011). Reducing 30-Day Emergency Readmissions (pp. 1-28). Retrieved from http://www.hsj.co.uk/Journals/2/Files/2011/6/15/Sg2_Ser vice Kit_Reducing 30-Day Readmissions.pdf
[6] Stratton, R. and Knight, A. (2010). Managing patient flow using time buffers. Journal of Manufacturing Technology Management, 21 (4), pp. 484-498.

[7] Burton Hospital. (2010). Discharge Policy. Burton. Retrieved from http://www.burtonhospitals.nhs.uk/corporate/docs/policie s/Discharge_36.pdf.

[8] Al-Mudimigh, A. S., Ullah, Z., \& Shahzad, B. (2010). A model for the efficient implementation of portals. 2010 2nd International Conference on Computer Engineering and Technology, 7, 552-554. doi:10.1109/ICCET.2010.5485596.

[9] Knott, L. (2012). Records, Computers and Electronic Health Record. Patient.co.uk. Retrieved January 07, 2013, from http://www.patient.co.uk/doctor/RecordsComputers-and-Electronic-Health-Record.htm.

[10] Nemeth, E. M. (2007). Build it [ right ] and They Will Come Clinical Portal Technology, 1-9.

[11] Johnston, D. (2002). Merger of Knowledge Management and Information Technology in Healthcare: Opportunities and Challenges. Evolution, 1-6.

[12] Malhotra, Y. (2000). Knowledge Management \& New Organization Forms : A Framework for Business Mode Innovation Knowledge Management \& New Organization Forms : A Framework for Business Model Innovation. Information Resources Management Journal, 13(1), 5-14. NHS (2012). About the NHS. [Online]. 2012.

[13] NHS. Available from: http://www.nhs.uk/NHSEngland/thenhs/about/Pages/ove rview.aspx. [Accessed: 10 November 2012].

[14] National Patient Safety Agency. (2012). Medical Error. London. 
[15] National Prescribing Centre. (2013). Reducing Medication Errors (p. 2). Retrieved from http://www.npc.nhs.uk/improving_safety/improving_safe ty/resources/Medication_Error/Reducing_5mg.pdf.

[16] Nonaka, I. (2007). Organizational Knowledge Creation. In The Knowledge Advantage Conference. Retrieved from nurture.com/downloads/NONAKA.pdf.

[17]. Wiig, K. M. (2002). New Generation Knowledge Management: What May We Expect? Knowledge Research Institute, Inc. 1, 1-9.

[18] Grant, K. A., \& Grant, C. T. (2008). Developing a Model of Next Generation Knowledge Management Stage I : Knowledge as the Domain of Philosophers and Scientists, 5 .

[19] Johnson, P., \& Nile, C. (2011). Discharge of patients from hospital policy (pp. 1-28). Doncaster. Retrieved from

http://www.dbh.nhs.uk/Library/Patient_Policies/PAT PA 3 v. 4 - Discharge of Patients from Hospital Policy.pdf.

[20] Nonaka, I., \& Lewin, A. Y. (1994). Dynamic Theory Knowledge of Organizational Creation. Organization Science, 5(1), 14-37. Retrieved from:http://www.ecampus.uvsq.fr/claroline/backends/do wnload.php?url $=\mathrm{L} 05 \mathrm{vbmFrYTk0LnBkZg}==\& \operatorname{cidReset}=\mathrm{t}$ rue\&cidReq=MDSDM105Accessed $9^{\text {th }}$ January 2015.

[21] Hannan, A. (2011). Real-Time Digital Medicine, at Christie Hospital Manchester. Available at: http://www.htmc.co.uk/pages/pv.asp?p=htmc0322. Accessed on 5th December 2014.

[22] Family Caregiver Alliance. (2012). Hospital Discharge Planning: A Guide for Families and Caregivers. Family Caregiver Alliance. Retrieved October 04, 2012, from http://www.caregiver.org/caregiver/jsp/content_node.jsp ?nodeid $=2312$.

[23] Kripalani, S., Jackson, A. T., Schnipper, J. L., \& Coleman, E. a. (2007). Promoting effective transitions of care at hospital discharge: a review of key issues for hospitalists. Journal of Hospital Medicine: An Official Publication of the Society of Hospital Medicine, 2(5), 314-23. doi:10.1002/jhm.228.

[24] Mamon, J., Steinwachs, D. M., Fahey, M., Bone, L. R., Oktay, J., \& Klein, L. (1992). Impact of hospital discharge planning on meeting patient needs after returning home. Health Services Research, 27(2), 155$75 . \quad$ Retrieved from http://www.pubmedcentral.nih.gov/articlerender.fcgi?arti $\mathrm{d}=1069871 \&$ tool=pmcentrez\&rendertype $=$ abstract.

[25] Dwivedi, A., Bali, R. K., James, a. E., Naguib, R. N. G., \& 10. Johnston, D. (2002). Merger of knowledge management and information technology in healthcare: opportunities and challenges. In IEEE CCECE2002. Canadian Conference on Electrical and Computer Engineering. Conference Proceedings (Cat. No.02CH37373) (pp. 1194-1199). Ieee. doi:10.1109/CCECE.2002.1013118.

[26] Umble, M., \& Umble, E. J. (2006). Utilizing buffer management to improve performance in a healthcare environment. European Journal of Operational Research, 174(2), 1060-1075. Retrieved from
http://www.sciencedirect.com/science/article/pii/S03772 $21705002948 \#$. Accessed $5^{\text {th }}$ January 2015.

[27] Kiely, R., \& Green, T. (2011). Delayed Transfers of Care (pp. 2-36). Birmingham, England.

[28] Curry, G. Procter, S.J. (2005). The Antecedents of Middle Managers' Strategic Contribution: The Case of a Professional Bureaucracy. Journal of Management Studies. Volume 42, Issue 7, Pp. 1325-1356.

[29] Bali, R.K. and Dwivedi, A. Healthcare Knowledge Management: Issues, Advances and Successes. Springer, New York.

[30] Davenport, T.H. and Prusal, L. (2000) Working Knowledge: How Organisations Manage What They Know. Harvard Business School Press. Boston.

[31] The Economist Intelligence Unit. (2005). Know how: Managing knowledge for competitive advantage (pp. 118). London. Retrieved from http://graphics.eiu.com/files/ad_pdfs/Tata_KnowHow_W P.pdf.

[32] Surrey and Sussex Healthcare NHS Trust. (2012). Safety and Quality Committee Chair Update (pp. 1-3) Retrieved from http://www.surreyandsussex.nhs.uk/_uploads/documents/ board_papers/2012/august/safety-and-quality-committeechair-update-3rd-aug.pdf.

[33] Discharge Planning and ALC Policy Task Team. (2006). Discharge from Hospital, (November).

[34] Metro (2012). NHS targets risk patients safety. Metro. [Online]. p.p. 1. Available from http://www.metro.co.uk/news/818656-nhs-targets-riskpatients-safety.

[35] Department of Health: Media Centre. (2011). Speech: 7 December 2011, Andrew Lansley, A Patient Centred NHS. Department of Health. Retrieved February 20, 2012 , http://mediacentre.dh.gov.uk/2011/12/07/speech-7december-2011-andrew-lansley-a-patient-centred-nhs/.

[36] McMurray, A., Johnson, P., Wallis, M., Patterson, E., \& Griffiths, S. (2007). General surgical patients' perspectives of the adequacy and appropriateness of discharge planning to facilitate health decision-making at home. Journal of Clinical Nursing, 16(9), 1602-9. doi:10.1111/j.1365-2702.2006.01725.x.

[37] Fontaine, M., \& Lesser, E. (2002). Challenges in managing organizational knowledge (pp. 1-5). Retrieved from http://www-935.ibm.com/services/us/imc/pdf/g5103234-00-esr-managing-organizational-knowledge.pdf.

[38] Lynch, N. (2011). A Qualitative Study into Patient Experiences of Discharge from Hospital to the Community (pp. 1-73). Birmingham, England. Retrieved from http://www.solihullsilc.org.uk/p/documents/solihull_link_and_birmingham_1 ink_discharge_from_hospital_to_the_community_report _1326712262.pdf.

[39] Hogan, H., Healey, F., Neale, G., Thomson, R., Vincent, C., \& Black, N. (2012). Preventable deaths due to problems in care in English acute hospitals: a retrospective case record review study. BMJ Quality \& Safety, (July). doi:10.1136/bmjqs-2012-001159. 
[40] The National Advisory Group on Safety of Patients in England. (2013). Improving the Safety of Patients in England. Retrieved from https://www.gov.uk/government/uploads/system/uploads /attachment_data/file/226703/Berwick_Report.pdf

[41] The Royal Pharmaceutical Society of Great Britain. (2006) Moving patients, moving medicines, moving safely. Guidance on discharge and transfer planning. Retrieved from http://psnc.org.uk/wpcontent/uploads/2013/07/Moving20Medicines20new1.pd f. Accessed on $5^{\text {th }}$ January 2015.

[42] Wilson-Evans Consulting Ltd. Report to the Institute for Healthcare $22^{\text {nd }}$ Annual National Forum orlando, Florida December $5^{\text {th }}-8^{\text {th }} 2010$. Available at http://wilsonevans.com/2010/12/17/the-institute-for-healthcareimprovement-annual-conference-2010/ Accessed on $5^{\text {th }}$ January 2015.

[43] NHS Scotland. (2013). Delayed Discharge. Report of the Expert Group Executive summary. Retrieved from http://www.scotland.gov.uk/Resource/Doc/924/0122015. pdf.

[44] Discharge from Hospital: Literature Review. (2006) DP and ALC Policy Task Team. Retrieved from:www.nelhin.on.ca/ /.../ALC/Literature_Review_ Hospital_Dis.pdf. Accessed on $7^{\text {th }}$ January 2015 .

[45] Department of Health. (2012). Delayed Transfers of Care Information. Retrieved November 10, 2012, from http://transparency.dh.gov.uk/2012/06/21/dtocinformation/.

[46] NHS National Services Scotland. (2012). Delayed Discharges Definitions and Data Recording Manual. Retrieved from http://www.isdscotland.org/HealthTopics/Health-and-Social-Community-Care/DelayedDischarges/Guidelines/delayed-discharges-manual120613.pdf.

[47] Panis LJ, Gooskens M, Verheggen FW, Pop P, Prins MH. (2003) Predictors of inappropriate hospital stay: a clinical case study. International Journal of Quality Health Care. February 15(1) Pp. 57-65.

[48] Barton, P., Bryan, S., Glasby, J., Hewitt, G., Jagger, C., Kaambwa, B., Martin, G., Nancarrow, S., Parker, S., Regen, E. \& Wilson, A. (2006) . A National Evaluation of the Costs and Outcomes of Intermediate Care for Older People, Leicester: Leicester Nuffield Research Unit.

[49] Foss, C., \& Hofoss, D. (2011). Elderly persons' experiences of participation in hospital discharge process. Patient Education and Counseling, 85(1), 68-73. doi:10.1016/j.pec.2010.08.025

[50] Anthony D, Chetty VK, Kartha A, McKenna K, DePaoli RM, Jack B. (2005) Patient safety at time of dischargean example of a multifaceted process evaluation. In: Henriksen K, Battles JB, Marks ESL, Lewin DI, editors. Advances in Patient Safety: From research to Implementation. vol. 2. Concepts and Methodology. Agency for Healthcare Research and Quality; Rockville, MD.

[51] Kamalanathan, N.A. Eardley, W.A. Chibelushi, C. Kingston, P. (2013) The Discharge Planning Dilemma in the UK NHS: The Role of Knowledge Management.
Health Information Science Lecture Notes in Computer Science Volume 7798, Pp. 172-185.

[52] Eardley, W.A. and Czerwinski, A. (2007) Knowledge Management for Primary Healthcare Services. In: R. Bali and A. Dwivedi, (Eds.), Knowledge Management: Issues, Advances and Successes, Springer Science + Business Media, New York, 2007.

[53] Kamalanathan, N.A. Eardley, W.A. Chibelushi, C., Colins, T. (2013) Improving the Patient Discharge Planning Process through Knowledge Management by Using the Internet of Things. Advances in Internet of Things Vol.3 No.2A(2013), Article ID:33250. Available at: http://file.scirp.org/Html/3-4000057_33250.htm. Accessed $7^{\text {th }}$ January 2015.

[54] Murray, P. . (1989). Rehabilitation information and health beliefs in the post-coronary patient: do we meet their information needs? Journal of Advanced Nursing, 14, 686-693. Retrieved from http://onlinelibrary.wiley.com/doi/10.1111/j.13652648.1989.tb01612.x/pdf

[55] Wyatt, J. C. (2001). Management of explicit and tacit knowledge. Journal of the Royal Society of Medicine, $94,6-4$.

[56] Sveiby, K. (2001). Knowledge Management - Lessons from the Pioneers. Knowledge Management - Lessons from the Pioneers, 3-9.

[57] Holsapple, C. W., \& Joshi, K. D. (2001). Organizational knowledge resources. Decision Support Systems, 31(1), 39-54. doi:10.1016/S0167-9236(00)00118-4.

[58] Roy, R., Rey, F. M., Wegen, B. Van, \& Steele, A. (2000). A Framework To Create Performance Indicators In Knowledge Management. In Proc. of the Third Int. Conf. on Practical Aspects of Knowledge Management (PAKM2000) (pp. 30-31). Basel, Switzerland. Retrieved from http://sunsite.informatik.rwthaachen.de/Publications/CEUR-WS/Vol-34/.

[59] Care Quality Commission. (2013). Inpatient survey 2012 (p. 19). United Kingdom. Retrieved from http://www.cqc.org.uk/public/reports-surveys-andreviews/surveys/inpatient-survey-2012.

[60] NHS (2014). Map of Medicine. Available at: http://www.mapofmedicine.com/. Accessed: 10 December 2014.

[61] [61]. NHS IC (2014). The NHS IC Indicator Portal.. NHS, The Information Centre for Health and Social Care. Available at: https://indicators.ic.nhs.uk/webview/. Accessed: 8th December 2014.

[62] Spindel, D. (2009). Patient-Provider Internet Portal Improves Operations, Clinical Care, and Patient Satisfaction, 58(5)

[63] The Christie NHS Foundation Trust (2014). Feedback on portal rollout. NHS. Available at: http://www.christie.nhs.uk/the-foundationtrust/treatments-and-clinical-services/gp/feedback.aspx Accessed on: 8th December 2014.

[64] Syvertsen, C. (2005). Institut for Informatikk INF5210 Project Clinical Portal at Rikshospitalet Document evolution, (October), Pp. 1-15. 
[65] Laff, M. (2014). Given Time, "Big Data"Promises to Transform Patient Care -- AAFP News -- AAFP. American Academy of Family Physicians.. Available from: http://www.aafp.org/news/practice-professionalissues/20140827qa-bigdata.html. Accessed on: 11th December 2014

[66] RevSpring (2014). Demystifying "Big Data" and Making It Work for Patient Account Managers. [Online]. 2014. The Pulse. Available from: http://www.revspringinc.com/blog-
healthcare/demystifying-\%E2\%80\%9Cbig-

data\%E2\%80\%9D-and-making-it-work-patient-accountmanagers. [Accessed: 11 December 2014].

[67] Billings, J., Blunt, I., Steventon, A., Georghiou, T., Lewis, G., \& Bardsley, M. (2012). Development of a predictive model to identify inpatients at risk of readmission within 30 days of discharge (PARR-30). BMJ Open, 2(4). Retrieved from http://bmjopen.bmj.com/content/2/4/e001667.full.pdf+ht $\mathrm{ml}$ 